Received: March 31, 2017

Accepted: April 20, 2017

Published: June 28, 2017

\section{Self-massage and Autonomic Response: Future Direction}

\author{
Estêvão Rios Monteiro ${ }^{1, *}$,Brent Wakefield ${ }^{2}$,Aline Gomes Ferreira de Melo Fiuza \\ ${ }^{1}$,Julio Cesar de Oliveira Muniz Cunha ${ }^{1,3}$,Victor Gonçalves Corrêa Neto ${ }^{1,4}$ and Jef- \\ ferson da Silva Novaes ${ }^{1}$ \\ ${ }^{1}$ School of Physical Education and Sports, Federal University of Rio de Janeiro, Rio de \\ Janeiro, Brazil \\ ${ }^{2}$ Center of Bone and Muscle Healthy, Brock University, Ontario, Canada \\ ${ }^{3}$ Estacio de Sá University, Rio de Janeiro, Brazil. \\ ${ }^{4}$ Gama e Souza College - Rio de Janeiro, Brazil
}

*Corresponding author: Estêvão Monteiro, BSc, School of Physical Education and Sports, Federal University of Rio de Janeiro, 540, Carlos Chagas Filho Avenue, 21941-599, Rio de Janeiro, Brazil, Tel:+552125626808 ;Fax: +552125626808; E-mail: profestevaomonteiro@gmail.com

\section{Abstract}

Self-massage (SM) is an active technique where participants use various instruments to apply pressure to soft tissue with an attempt to mimic manual therapy techniques. Within the literature, there are many techniques associating positive responses to the phenomena controlled by the central nervous system (i.e. stretching and manual therapies). The purpose of this short communication is to present the literature regarding similar techniques to SM and their effects on the central nervous system. Furthermore, there is no research investigating the safety of performing SM techniques prior to performance. Considering SM is non-invasive and practical, findings of such research would be applicable in clinical and performance settings. Thus, the authors encourage further research that satisfies the needs of these gaps.

\section{Keywords}

Foam rolling; heart rate variability; rolling massage; selfmanual therapy; self-myofascial release

\section{Short Communication}

Self-massage (SM) is an active technique [1], where participants use foam rollers, lacrosse balls or rolling sticks to apply pressure to soft tissue with the goal of breaking up adhesions between skeletal muscle and the surrounding connective tissue.Foam rollers are a nonuniform cylinder consisting of a hol- low hard inner core enclosed in a layer of ethylene vinyl acetate foam [2] and roller massagers are devices involving dense foam wrapped around a solid plastic cylinder [3], but differ from foam rollers as they have a central axle that is grasped by the hands and rolled over the tissue of interest[3]. It is common for SM to be prescribed at low loads for long durations [4].Usually, SM can be performed via foam rolling or rolling massage and is used to acutely facilitate joint range-of-motion $[2,5,6]$ without decreasing performance $[7,8]$ or not $[9,10]$ and reduce delayed onset muscle soreness $[11,12]$. While it is believed that SM techniques can provide structural changes to connective tissue such as fascia, there is no evidence to support this mechanism[3].

There is literature suggesting neural mechanisms explain performance alterations post static stretching, which may explain the benefits from SM. For example, Drew et al. [13] observed that spontaneous baroreflex sensitivity decreased with increasing contraction intensity with subsequent local circulatory occlusion. After 15-seconds of stretching, heart rate increased $6 \pm 1,6 \pm 1$, $8 \pm 1$, and $6 \pm 2$ for $0,30,50$, and $70 \%$, respectively. The authors suggest that passive calf muscle stretching decreases cardiac vagal outflow irrespective of the levels of blood pressure increase caused by muscle metaboreflex activation, and implies that central modulation of baroreceptor input, mediated by the actions of stretch-activated mechanoreceptive muscle afferent fibers. Results of Farinatti et al. [14,15]found that sympathetic activity increased during stretching, while parasympathetic activity increased post-stretching. Costa e Silva et al. [16] found hypotensive effects after stretching exercises with low volumes. It is suggested that static stretching results in activation of type III fibers and metaboreceptors in skeletal muscle, resulting in an inhibition of the vagal and baroreflex stimulation, thus contributing to cardiovascular alterations. These results demonstrate an isolated 
stretching exercise rather than a session, which is suggested by the American College of Sports Medicine [17].Many studies investigated pre- and post-intervention, but not during physical exercise. However, Farinatti et al. [14, 15] found significant blood pressure responses during stretching exercises.

Literature shows similar effects for other techniques (i.e. Stretching and/or massage). Monteiro et al. [9] report that manual therapies produces a descending inhibitory response via endogenous opioids and other neuropeptides acting on the periaqueductal grey and rostral ventromedial medulla, which produces an analgesia effects. These effects appear to be mediated by the autonomic nervous system, with modulation of sympathetic and parasympathetic tone [18]. The autonomic nervous system mechanisms are not clear enough, but massage has been associated with changes in stress hormones (cortisol and neuropeptides), endogenous opioids, oxytocin, endocannabinoids, dopamine and serotonin $[19,20]$.

It is believed that manual therapies answer may be extrapolated for SM, however, only one study tested for cardiac responses [21]. Okamoto et al. [21] tested the effectively of SM by foam rolling on arterial stiffness and vascular endothelial function for brachial-ankle pulse wave velocity and plasma nitric oxide (NO) values. Participants performed 20 SM repetitions for thigh adductor, hamstring, quadriceps, iliotibial band, and trapezius by foam rolling. Authors found significant decreases of brachialankle pulse wave velocity (from 1,202 \pm 105 to $1,074 \pm 110$ $\mathrm{cm} . \mathrm{s}^{-1}$ ) and increased no plasma concentration (from $20.4 \pm 6.9$ to $34.4 \pm 17.2 \mu \mathrm{mol} . \mathrm{L}^{-1}$ ), but neither significantly different after control trials. These results indicate that SM by foam rolling reduces arterial stiffness and improves vascular endothelial function.

To our knowledge, no other published studies have examined the SM effect of autonomic response. However, our unpublished data collected suggests an important and significant hemodynamics and autonomic response, such as hypotensive effect and higher heart rate variability values. As mentioned above, SM is characterized as an active technique which participants perform themselves [1] and requires higher energy to complete the task. Physical exercise performance may lead to compensatory flattening of the sympathetic discharge with synergistic increase of the parasympathetic component at post-exercise moments, which illustrated the autonomic activity of blood pressure reduces at postexercise moments [22].

The present short communication purposes are to show the current literature regarding static stretching and SM and their effects on the central nervous system. Furthermore, there is no literature to our knowledge investigating the safety concerns associated with SM and the risk to benefit relationship. While SM is commonly used in clinical and performance settings due to the fact that it is convenient and inexpensive alternative to manual therapy, the safety of its application has never been assessed. Thus, the authors encourage further research that satisfies the needs of these gaps.

\section{References}

1. Monteiro ER, Corrêa Neto VG. Effect of different foam rolling volumes on knee extension fatigue. Int J Sports Phys Ther. 2016;11(7):1076-1081.

2. Curran PF, Fiore RD, Crisco JJ. A comparison of the pressure exerted on tissue by 1 myofascial roller. J Sport Rehabil. 2008;17(4):432-442.

3. Beardsley C, Škarabot J. Effects of self-myofascial release: A systematic review. J Bodyw Mov Ther. 2015;19(4):747-758. Doi: 1dx.doi.org/10.1016/j.jbmt.2015.09.007

4. Ajimsha MS, Al-Mudahka NR, Al-Madzhar JA. Effectiveness of miofascial release: Systematic review of randomized controlled trials. J Bodyw Mov Ther. 2015;19(1):102-112. Doi: 10.1016/j.jbmt.2014.06.001.

5. Cheatham SW, Kolber MJ, Cain M, Lee M. The effects of self-myofascial release using a foam roll or roller massager on joint range of motion, muscle recovery, and performance: A systematic review. Int J Sports Phys Ther. 2015;10(6):827-838.

6. Monteiro ER, Cavanaugh MT, Frost DM, Novaes JS. Is self-massage an effective joint range-of-motion strategy? A pilot study. J Bodyw Mov Ther. 2017;21(1):223-226. Doi: dx.doi.org/10.1016/j.jbmt.2016.10.003

7. Halperin I, Aboodarda SJ, Button DC, Andersen LL, Behm DG. Roller massager improves range of motion of plantar flexor muscle without subsequent decreases in force parameters. Int J Sports Phys Ther. 2014;9(1):92-102.

8. Sullivan KM, Silvey DBJ, Button DC, Behm DG. Roller massager application to the hamstrings increases sit-and-reach range of motion within five to ten seconds without performance impairments. Int J Sports Phys. 2013;8(3):228-236.

9. Monteiro ER, Škarabot J, Vigotsky AD, Brown AF, Gomes TM, Novaes JD. Maximum repetition performance after different antagonist foam rolling volumes in the inter-set rest period. Int $\mathrm{J}$ Sports Phys Ther. 2017;12(1):76-84.

10. Monteiro ER, Vigotsky AD, Škarabot J, Brown AF, Fiuza AGFM, Gomes TM, Halperin I, Novaes JD. Acute effects of different foam rolling volumes in the inter-set rest period on maximum repetition performance. Manuscript submitted for publication. 2017;12(1):94-104.

11. MacDonald GZ, Button DC, Drinkwater EJ, Behm DG. Foam rolling as a recovery tool after an intense bout of physical activity. Med Sci Sports Exerc. 2014;46(1):131-142. Doi: 10.1249/MSS.0b013e3182a123db.

12. Pearcey GE, Bradbury-Squires DJ, Kawamoto JE, Drinkwater EJ, Behm DG, Button DC. Foam rolling for delayed-onset muscle soreness and recovery of dynamic performance measures. J Athl Train. 2015;50(1):5-13. Doi: 10.4085/1062-6050-50.1.01.

Citation:Monteiro ER,Wakefield B,Ferreira de Melo Fiuza GM,de Oliveira Muniz Cunha JC,Corrêa Neto VG, da Silva Novaes J(2017), Self-massage and Autonomic Response: Future Direction.J Excer Sports Orthop 4(2): 1-3 
13. Drew RC, Bell MP, White MJ. Modulation of spontaneous baroreflex control of heart rate and indexes of vagal tone by passive calf muscle stretch during graded metaboreflex activation in humans. J Appl Physiol. 2009;104(3):716-723. Doi: 10.1152/ajpheart.00061.2009.

14. Farinatti PTV, Brandão C, Soares PPS, Duarte AFA. Acute effect of stretching exercise on heart rate variability in subjects with low flexibility levels. J Strength Cond Res. 2011;25(6):1579-1585. Doi: 10.1519/JSC.0b013e3181e06ce1.

15. Farinatti PTV, Soares PPS, Monteiro WD, Duarte AFA, Castro LAV. Cardiovascular responses to passive static flexibility exercise are influenced by stretched muscle mass and Valsalva maneuver. Clinics. 2011;66(3):459-464. Doi: 10.1590/S180759322011000300017

16. Costa e Silva G, Di Mais F, Paixão A, Bentes CM, Sá M, Miranda H, Simão R, Novaes J. Effects of proprioceptive neuromuscular facilitation stretching and static stretching on cardiovascular responses. JEPOnline. 2013;16:117-125.

17. American College of Sports Medicine. Quantity and quality of exercise for developing and maintaining cardio respiratory, musculoskeletal, and neuromotor fitness in apparently healthy adults: Guidance for prescribing exercise. Med Sci Sports Exerc.
2011;43(7):1334-1359. Doi: 10.1249/MSS.0b013e318213fefb.

18. Bazzichi L, Dini M, Rossi A, Corbianco S, Giovannoni E, Consensi A, et al. A combination therapy of massage and stretching increases parasympathetic nervous activity and improves joint mobility in patients affects by fibromyalgia. Healthy (Irvine Calif). 2010;2(8):919-926. doi: 10.4236/healthy.2010.28136.

19. Field T, Hernandez-Reif M, Diego M, Schanberg S, Kuhn C. Cortisol decreases and serotonin and dopamine increase following massage therapy. Int J Neurosci. 2005;115(10):13971413. Doi: 10.1080/00207450590956459

20. Vigotsky $\mathrm{AD}$, Bruhns RP. The role of descending modulation in manual therapy and its analgesic implications: A narrative review. Pain Res Treat. 2015;2015:192805. Doi:10.1155/2015/292805.

21. Okamoto T, Masuhara M, Ikuta K. Acute effects of self-myofascial release using a foam roller on arterial function. J Strength Cond Res. 2014;28(1):69-73. Doi: 10.1519/JSC.0b01e31829480f5.

22. MacDonald JR. Potential causes, mechanisms and, implications of post exercise hypotension. J Hum Hypertens. 2002;16(4):225-236. Doi: 10.1038/sj.jhh.1001377 